\title{
Cognition after major surgery in the elderly: test performance and complaints
}

\author{
J. B. Dijkstra*, P. J. Houx and J. Jolles \\ Maastricht Brain and Behaviour Research Institute and Department of Psychiatry and Neuropsychology, \\ University of Maastricht, The Netherlands \\ *Corresponding author: Department of Psychiatry and Neuropsychology, Academic Hospital Maastricht, \\ P. Debyelaan 25, PO Box 5800, 6202 AZ Maastricht, The Netherlands
}

\begin{abstract}
There is evidence that older people in particular have a higher risk of cognitive dysfunction after surgery under general anaesthesia. W e have investigated the severity and character of postoperative cognitive dysfunction after major non-cardiac surgery in patients older than $65 \mathrm{yr}$. Also, cognitive complaints were studied. Cognitive function was assessed using cognitive tests measuring memory and attention, such as ability to shift between two sequences, ability to ward off distractions, simple cognitive speed and speed of general information processing. These tests were performed before, 1 week (short-term) and 3 months (long-term) after surgery. Cognitive performance of the patients was compared with that of healthy subjects not undergo ing surgery who were also subjected to repeated cognitive measurements. After 1 week, patients had a poorer performance on tests measuring simple cognitive speed and speed of general information processing. Three months after surgery, patients and controls showed improved cognitive performance compared with the first measurement. These results suggest that major non-cardiac surgery in older patients causes short-term but not long-term cognitive dysfunction. However, after 6 months, 14 of 48 patients (29\%) reported having experienced a decline in cognitive abilities after discharge from hospital. Eight of these 14 patients (17\%) were still experiencing these cognitive complaints and reported 'not being the same since the operation'. These findings emphasize that cognitive complaints after major surgery may not reflect actual changes in cognitive performance but may be caused by other factors such as depression or awareness of age-related changes.
\end{abstract}

Br J Anaesth 1999; 82: 867-74

Keywords anaesthesia, geriatric; age factors; psychological responses, postoperative Accepted for publication: February 1,1999

Postoperative cognitive dysfunction is not uncommon in elderly patients after major surgery. Many clinicians have described patients who underwent an uncomplicated operation under general anaesthesia, but who complained after operation for weeks to months of psychological dysfunction. ${ }^{1-4}$ For some patients who suffer transient (weeks to months) cognitive impairment, complaints may cause only annoyance; for others they may constitute a serious crisis, especially if cognitive impairment is permanent and results in loss of job or, in the elderly, loss of independence. Several studies have described early postoperative cognitive dysfunction $^{5-8}$ whereas long-term (weeks to months) postoperative cognitive dysfunction is seldom found. However, a substantial number of patients have cognitive complaints for a long period after operation. ${ }^{2-4}$

The discrepancy between cognitive complaints and cognitive test performance may be caused by the methodological weaknesses of previous studies. Most studies have used insensitive tests such as the mini-mental state examination (MMSE). ${ }^{9-12}$ Another problem is the lack of parallel versions of the cognitive tests and lack of healthy control groups. ${ }^{7-8}$ This means that postoperative deterioration in test performance could be obscured by learning effects (i.e. performance improves from test session to test session). This phenomenon could be the reason why there is sometimes no objective decline in test performance after operation even though a patient has cognitive complaints. ${ }^{2}$

The principal aim of this study was to evaluate postoperative cognitive dysfunction (short- and long-term) and investigate the correlation between objective cognitive performance and self-reported cognitive dysfunction in the long term. Also, several predictors (duration of anaesthesia, hospitalization time) were studied as possible risk factors for development of postoperative cognitive dysfunction. The study was performed within the framework of the International Study on Postoperative Cognitive Dysfunc- 
tions (ISPOCD), which is part of a Biomed European concerted action programme in European countries and the USA involving 1218 elderly subjects who have undergone an operation under general anaesthesia. ${ }^{13}$

\section{Patients and methods}

We studied 56 elderly patients who underwent surgery under general anaesthesia at the Academic Hospital, Maastricht, The Netherlands. Eligible patients were aged at least $60 \mathrm{yr}$, and had presented for major abdominal, thoracic, non-cardiac or orthopaedic surgery under general anaesthesia between May 1995 and May 1996, with an expected hospital stay of at least 4 days. The study was approved by the Medical Ethics Committee and informed consent was obtained from patients. Exclusion criteria were: patients with major psychiatric disease; diseases of the central nervous system (recent meningitis or encephalitis, tumours, major degenerative diseases and cardiovascular accident); those receiving major tranquillizers and antidepressants; those undergoing neurosurgery or cardiac surgery; those unable or unwilling to abide by the study procedure; those who could not follow procedures or who had poor comprehension of the Dutch language; those with severe visual or auditory disorder/handicaps, clinically significant Parkinson's disease, or a current diagnosis of alcoholism or drug dependence; those not expected to be discharged from hospital alive; or those whose postoperative hospital stay was expected to be shorter than 4 days. All patients scored higher than 23 on the MMSE. In total, 48 patients were used in the final analysis: three patients died shortly after operation, two patients were too ill to perform the neuropsychological tests after operation and three patients refused to participate after operation.

A control group of 50 healthy volunteers was recruited by an advertisement in a local newspaper. The same inclusion criteria were used for the control group.

Patients received a benzodiazepine orally or an opioid i.m., before induction of anaesthesia. General anaesthesia comprised one of two standard techniques: (1) a potent inhalation agent (enflurane, isoflurane or halothane), nitrous oxide in oxygen and fentanyl, or (2) i.v. anaesthesia with nitrous oxide in oxygen. Anaesthesia was induced in all patients with thiopental $2-5 \mathrm{~kg}^{-1}$. For neuromuscular block, pancuronium or atracurium was used, and residual block was antagonized with neostigmine $2.5 \mathrm{mg}$ and atropine $1.0 \mathrm{mg}$ at the end of surgery.

\section{Measurements}

Visual verbal learning test (VVLT)

This is a computerized, visual version of a test of secondary memory. In three consecutive trials, a list of 15 words is memorized and reproduced. The dependent variable is the total number of words recalled over the three trials (VVLTTOT). VVLT also involves delayed recall after
$20 \mathrm{~min}$, thus enabling measurement of memory retrieval (VVLTDEL). ${ }^{14}$

\section{Stroop colour-word test (SCWT)}

The SCWT has often been used to test selective attention, mental speed and interference susceptibility. ${ }^{15}$ The test involves three cards displaying 40 stimuli each: colour names (SCWT I), coloured patches (SCWT II) and colour names printed in incongruously coloured ink (SCWT III). The dependent variables are the time needed to read (SCWT I) or to name the colour of the patches (SCWT II) or printing ink (SCWT III).

\section{Concept shifting test (CST)}

This test is derived from the trail making test, which has long been used to measure the ease of shifting between concepts in ongoing behaviour. ${ }^{16}$ It consists of four parts. On each test sheet, 16 small circles are grouped in a larger circle. In the first part, empty circles are crossed out as fast as possible (CST0). In the other three parts, the circles contain numbers (CSTA), letters (CSTB), or both (CSTC), appearing in a fixed random order. Subjects are requested to cross out the items in the right order. The dependent variable is the time needed to complete each part.

\section{Letter-digit substitution test (LDST)}

This test is a modification of the procedurally identical symbol-digit modalities test. ${ }^{17}$ Subjects are supplied with a code at the top of a page where a digit corresponds to a letter. They then have a short time to fill in blanks which correspond to the correct codes. The test is used to measure the speed of processing of general information. The dependent variable is the total number of letters written correctly in $1 \mathrm{~min}$ (LDSTTOT).

\section{Affective state and self-reported cognitive dysfunction}

Feelings of depression were measured with the Zung selfrating scale for depression (Zung), ${ }^{18}$ which assesses if cognitive function is negatively influenced by depression. In order to estimate the percentage of patients suffering from long-term subjective cognitive dysfunction, and to assess if these self-reported complaints correspond to actual changes in cognitive performance, a short structured interview by telephone was conducted 6 months after discharge from hospital. In this interview, the patient was asked whether he/she had experienced changes in cognitive function after discharge from hospital and for how long.

Parallel versions of the LDST, CST and VVLT were developed in order to correct for learning effects as a result of repeated measurements. In the LDST, the code on top of the page was changed so that digits corresponded to different letters. In the CST, the place of the numbers and letters was changed. In the VVLT, different words were used.

The cognitive measurements assess the following theoretical underlying cognitive constructs: memory (VVLTTOT, VVLTDEL) and attention-related aspects such as cognitive flexibility (ability to shift between two 
sequences; CSTC), interference susceptibility (ability to ward off distractions; SCWT III), sensorimotor speed (simple cognitive speed; CST0, CSTA, CSTB, SCWT I and II), and speed of general information processing (LDSTTOT) ${ }^{19}$

\section{Procedure}

The cognitive test battery was administered on three occasions: 1 day before operation (baseline), and 7 days and 3 months after operation. On each occasion, a parallel version of the test battery was given in random order to reduce learning effects. Patient characteristics, medical, surgical and social histories, and medications used were obtained by means of an interview with the patient before operation. Depression was assessed on each occasion. The control group underwent the same procedure: they were tested at the same time intervals between cognitive measurements. These subjects considered themselves healthy; a formal evaluation of mood changes and cognitive complaints was not performed. The recruitment period for patients was $1 \mathrm{yr}$; inclusion of controls was completed in 4 months. Only complete cases were analysed.

\section{Data analysis}

Comparison of patients and controls was performed to control for the effect of repeated testing. To study the initial differences between the two groups on the 10 test variables, a $t$ test was used. A distinction was made between shortand long-term cognitive effects. A short-term effect was defined as a change in performance from baseline to 7 days after operation, and a long-term effect as a change from baseline to 3 months after operation. Because of the differences between patients and controls in age, years of education and sex distribution, a multiple regression analysis for each measurement was performed. Age and years of education showed an effect on test performance but no effect of sex was found; accordingly, sex was not analysed as a separate factor. For statistical evaluation of the effect of operation on cognitive performance, age and years of education were used as covariates to correct for the effect of these on test performance. The short- and long-term cognitive effects were tested by an univariate analysis of covariance with repeated measurements (ANCOVA).

In addition to changes in mean scores, it is important to consider individual changes. ${ }^{20}$ Variability in test scores is almost always substantially larger among patients than controls and such high variances could obscure differences in group means. Changes in performance between controls for each test from baseline (first session) to 1 week and 3 months were compared. The mean (SD) of these differences was calculated; this mean may be taken as estimated learning effects. For patients, baseline scores were compared with the 1 week and 3 month test results; the average learning effect was subtracted from these changes and divided by the SD of the control group to obtain a $\mathrm{z}$ score for each test. Patients had postoperative cognitive
Table 1 Patient characteristics (mean (SD or range) or number). $* * P<0.01$

\begin{tabular}{lcl}
\hline & Patients $(\boldsymbol{n}=\mathbf{4 8})$ & Controls $(\boldsymbol{n}=\mathbf{5 0})$ \\
\hline Age (yr) & $68.2(60-85)$ & $64.5(57-78)^{* * *}$ \\
Education (yr) & $9.2(2.9)$ & $11.2(3.3)^{* * *}$ \\
Sex (M/F) & $13 / 35$ & $27 / 23^{* *}$ \\
Anaesthesia time (min) & $164.3(66.8)$ & \\
Day of discharge & $10.4(5.7)$ & \\
Surgical procedure & & \\
Abdominal surgery & 16 & \\
Vascular surgery & 8 & \\
Urological surgery & 7 & \\
Gynaecological surgery & 6 & \\
Orthopaedic surgery & 4 & \\
Breast & 2 & \\
Other & 5 & \\
Reason for drop-out & 3 & \\
Death & 2 & \\
Too ill & 3 & \\
Refusal &
\end{tabular}

dysfunction when two of the $10 \mathrm{z}$ scores of the cognitive variables were 1.96 or more. This method of estimating individual cognitive change conforms to the method used in the ISPOCD study. ${ }^{13}$

To decide which intra-individual factors might contribute to a change in performance in the patient group, age, years of education, sex, change on the depression scale, duration of anaesthesia and days spent in hospital after the first postoperative measurement were entered in a stepwise hierarchical multiple regression model. Days spent in hospital after the first postoperative measurement was taken as a measure of the severity of illness after operation. It was assumed that patients who stayed in hospital for a longer period after their operation were more ill than patients who left hospital before the first postoperative measurement. This variable was used to study the effect of the medical condition on change in cognitive performance. The day of discharge was subtracted from the day of the first postoperative measurement. A positive score indicates a stay in hospital after the first postoperative measurement, a negative score indicates that the patient had left hospital before the first postoperative measurement.

In the first step of the regression analysis, age, years of education and sex were entered; in the second step, change in Zung, and in the third step, duration of anaesthesia and days spent in hospital were entered. Dependent variables were short- and long-term change score for the cognitive variables. These change scores were calculated in such a way that a negative difference indicated a decline and a positive difference an improvement. Both absolute change (in raw test score) and relative change (percentage change) were computed and analysed. $P<0.05$ was regarded as significant.

\section{Results}

The controls were, on average, 4 yr younger and had 2 years more education, and there were fewer women in the control group (Table 1). 
Table 2 Difference in baseline performance of patients and controls in various tests of cognitive function (mean (SD)) on raw test scores ( $t$ test) and test scores adjusted for age and years of education (ANCOVA). ${ }^{*} P<0.05$; $* * P<0.01$. For CST and SCWT, a higher score indicates a lower test performance. For VVLT and LDST, a lower score indicates a lower test performance

\begin{tabular}{|c|c|c|c|c|}
\hline & Patients $(n=48)$ & Controls $(n=50)$ & $\begin{array}{l}t \text { test } \\
t \text { value }\end{array}$ & $\begin{array}{l}\text { ANCOVA } \\
F(\text { df) }\end{array}$ \\
\hline \multicolumn{5}{|c|}{ Concept shifting test (CST) } \\
\hline $\begin{array}{l}\text { CST0 } \\
\text { CSTA } \\
\text { CSTB } \\
\text { CSTC }\end{array}$ & $\begin{aligned} 8.2 & (2.6) \\
25.5 & (7.3) \\
32.2 & (10.9) \\
43.7 & (15.7)\end{aligned}$ & $\begin{array}{r}6.4(1.2) \\
21.6(5.1) \\
25.5(5.8) \\
34.5(10.6)\end{array}$ & $\begin{array}{l}4.2 * * \\
3.0 * * \\
3.8^{* *} \\
3.4 * *\end{array}$ & $\begin{array}{l}7.1(1,94)^{* *} \\
0.6(1,94) \\
5.6(1,94)^{*} \\
3.2(1,93)\end{array}$ \\
\hline \multicolumn{5}{|c|}{ Visual verbal learning test (VVLT) } \\
\hline $\begin{array}{l}\text { VVLTTOT } \\
\text { VVLTDEL }\end{array}$ & $\begin{array}{r}25.1(6.0) \\
7.5(3.1)\end{array}$ & $\begin{array}{r}26.8(5.1) \\
9.2(2.5)\end{array}$ & $\begin{array}{l}-1.5 \\
-2.8 * *\end{array}$ & $\begin{array}{l}3.8(1,93) \\
1.7(1,93)\end{array}$ \\
\hline \multicolumn{5}{|c|}{ Stroop colour-word test (SCWT) } \\
\hline $\begin{array}{l}\text { SCWT I } \\
\text { SCWT II } \\
\text { SCWT III }\end{array}$ & $\begin{array}{l}17.0(3.0) \\
23.5(4.2) \\
55.8(20.1)\end{array}$ & $\begin{array}{l}18.1(2.9) \\
22.7(3.5) \\
37.5(8.2)\end{array}$ & $\begin{array}{l}-1.8 \\
1.0 \\
5.8 * *\end{array}$ & $\begin{array}{c}7.0(1,94)^{*} \\
0.1(1,92) \\
21.0(1,93)^{* *}\end{array}$ \\
\hline \multicolumn{5}{|c|}{ Letter-digit substitution test (LDST) } \\
\hline LDSTTOT & $26.2(7.4)$ & $31.6(7.2)$ & $-3.7 * *$ & $2.7(1,94)$ \\
\hline
\end{tabular}

Baseline performance of the patients was worse than that of the controls for seven of the 10 cognitive test variables (Table 2). These initial differences between the groups may have been caused by differences in age and education (Table 1). Analysis of covariance with age and education as covariates was used to study the differences in test performance after adjustment for these variables. Table 2 shows that patients still performed worse on three of the 10 test variables and performed better on one of the 10 test variables after adjustment for age and years of education.

\section{Short-term cognitive effects}

There were significant group effects for six of the 10 variables (Table 3). Patients performed worse than controls on tests measuring sensorimotor speed (CST0, CSTB, SCWT I), memory (VVLTDEL), interference susceptibility (SCWT III) and processing of general information (LDSTTOT). A time effect between the two measurements was found on one test measuring interference susceptibility (SCWT III); both groups showed improved performance. Interaction effects (group $\times$ time) were found in tests measuring sensorimotor speed (CST0, SCWT I and II) and general information processing (LDSTTOT). Patients showed a decline in performance and controls an improvement or no change.

\section{Long-term cognitive effects}

Significant group effects were found on five of the 10 variables (Table 4). Patients performed worse than controls on tests measuring sensorimotor speed (CST0, SCWT I), memory (VVLTDEL), interference susceptibility (SCWT III) and processing of general information (LDSTTOT). A time effect was found on sensorimotor speed (CST0, SCWT II), memory (VVLTTOT, VVLTDEL), interference susceptibility (SCWT III) and processing of general information
(LDSTTOT); both groups showed improvement. Interaction effects were found for one measure of sensorimotor speed (CSTB), interference susceptibility (SCWT III) and processing of general information (LDSTTOT). With respect to sensorimotor speed and interference susceptibility, both groups improved but patients improved more than controls. Patients improved less than controls for processing of general information.

\section{Individual cognitive change}

Results of the test performance of individual subjects are summarized in Table 5. At 1 week after surgery, cognitive dysfunction was found in $13(27 \%)$ of 48 patients compared with $6 \%$ of the control group $(P=0.048)$. Three months after operation, four $(8 \%)$ patients still had a poorer performance on two or more test variables compared with $2 \%$ in the control group (ns).

\section{Mood changes and cognitive complaints}

With respect to mood, no change in depressive symptoms was found in the patient group 1 week and 3 months after surgery compared with baseline $(t=-1.49$ (ns) and $t=-0.58$ (ns), respectively).

After 6 months, 14 patients $(29 \%)$ reported that they had experienced worsening of cognitive function after discharge from hospital, and eight (17\%) of these patients still suffered from cognitive dysfunction.

\section{Regression analysis}

Results of regression analysis showed a significant contribution of change on the Zung depression scale to change in performance in the concept shifting test (CST0) 3 months after operation, indicating poorer performance with higher Zung scores (more depressive symptoms). As shown in 
Table 3 Short-term effects of surgery on the performance of patients and controls in various tests of cognitive function. For each test, mean (SD) levels are displayed at baseline and 7 days after operation. For CST and SCWT, a higher score indicates a lower test performance. For VVLT and LDST, a lower score indicates a lower test performance

\begin{tabular}{|c|c|c|c|c|c|c|c|c|c|c|c|c|}
\hline & \multicolumn{3}{|c|}{ Patients } & \multicolumn{3}{|c|}{ Controls } & \multicolumn{2}{|l|}{ Group } & \multicolumn{2}{|l|}{ Time } & \multicolumn{2}{|c|}{ Group $\times$ time } \\
\hline & $n$ & Mean & (SD) & $n$ & Mean & (SD) & $\mathbf{F}(\mathbf{d f})$ & $P<$ & $F(d f)$ & $P<$ & F (df) & $P<$ \\
\hline \multicolumn{13}{|c|}{ Concept shifting test (CST) } \\
\hline $\operatorname{CST0}(\mathrm{s})$ & 48 & $\begin{array}{l}8.2 \\
8.3\end{array}$ & $\begin{array}{l}(2.6) \\
(2.4)\end{array}$ & 50 & $\begin{array}{l}6.4 \\
6.2\end{array}$ & $\begin{array}{l}(1.2) \\
(1.1)\end{array}$ & $10.9(1,94)$ & 0.01 & $0.1(1,96)$ & ns & $4.3(1,96)$ & 0.01 \\
\hline CSTA (s) & 48 & $\begin{array}{l}25.5 \\
26.6\end{array}$ & $\begin{array}{l}(7.3) \\
(6.8)\end{array}$ & 50 & $\begin{array}{l}21.6 \\
22.2\end{array}$ & $\begin{array}{l}(5.1) \\
(5.0)\end{array}$ & $2.0(1,94)$ & ns & $3.7(1,96)$ & ns & $0.4(1,96)$ & ns \\
\hline CSTB (s) & 48 & $\begin{array}{l}32.2 \\
32.0\end{array}$ & $\begin{array}{l}(10.9) \\
(11.0)\end{array}$ & 50 & $\begin{array}{l}25.5 \\
24.8\end{array}$ & $\begin{array}{l}(5.8) \\
(6.1)\end{array}$ & $6.4(1,94)$ & 0.05 & $0.4(1,96)$ & ns & $0.1(1,96)$ & ns \\
\hline $\operatorname{CSTC}(s)$ & 48 & $\begin{array}{l}43.7 \\
48.7\end{array}$ & $\begin{array}{l}(15.7) \\
(27.0)\end{array}$ & 49 & $\begin{array}{l}34.5 \\
34.1\end{array}$ & $\begin{array}{l}(10.6) \\
(10.9)\end{array}$ & $3.5(1,93)$ & ns & $2.2(1,95)$ & ns & $2.9(1,95)$ & ns \\
\hline \multicolumn{13}{|c|}{ Visual verbal learning test (VVLT) } \\
\hline VVLTTOT & 48 & $\begin{array}{l}25.1 \\
24.8\end{array}$ & $\begin{array}{l}(6.0) \\
(6.1)\end{array}$ & 49 & $\begin{array}{l}26.8 \\
26.6\end{array}$ & $\begin{array}{l}(5.1) \\
(5.3)\end{array}$ & $1.5(1,93)$ & ns & $0.4(1,95)$ & ns & $0.0(1,95)$ & ns \\
\hline VVLTDEL & 48 & $\begin{array}{l}7.5 \\
7.2\end{array}$ & $\begin{array}{l}(3.1) \\
(3.3)\end{array}$ & 49 & $\begin{array}{l}9.2 \\
8.5\end{array}$ & $\begin{array}{l}(2.5) \\
(2.7)\end{array}$ & $4.7(1,93)$ & 0.05 & $3.6(1,95)$ & $\mathrm{ns}$ & $0.5(1,95)$ & ns \\
\hline \multicolumn{13}{|c|}{ Stroop colour-word test (SCWT) } \\
\hline SCWT I (s) & 47 & $\begin{array}{l}17.0 \\
17.9\end{array}$ & $\begin{array}{l}(3.0) \\
(3.4)\end{array}$ & 50 & $\begin{array}{l}18.1 \\
17.6\end{array}$ & $\begin{array}{l}(2.9) \\
(2.9)\end{array}$ & $4.9(1,93)$ & 0.05 & $0.4(1,95)$ & ns & $7.0(1,95)$ & 0.01 \\
\hline SCWT II (s) & 46 & $\begin{array}{l}23.5 \\
24.1\end{array}$ & $\begin{array}{l}(4.2) \\
(3.9)\end{array}$ & 50 & $\begin{array}{l}22.7 \\
21.8\end{array}$ & $\begin{array}{l}(3.5) \\
(3.2)\end{array}$ & $0.4(1,92)$ & ns & $0.6(1,94)$ & ns & $8.6(1,94)$ & 0.01 \\
\hline SCWT III (s) & 47 & $\begin{array}{l}55.8 \\
52.0\end{array}$ & $\begin{array}{l}(20.1) \\
(18.1)\end{array}$ & 50 & $\begin{array}{l}37.5 \\
34.3\end{array}$ & $\begin{array}{l}(8.2) \\
(7.0)\end{array}$ & $24.9(1,93)$ & 0.001 & $17.8(1,95)$ & 0.001 & $0.1(1,95)$ & ns \\
\hline \multicolumn{13}{|c|}{ Letter-digit substitution test (LDST) } \\
\hline LDSTTOT & 48 & $\begin{array}{l}26.2 \\
25.4\end{array}$ & $\begin{array}{l}(7.4) \\
(7.5)\end{array}$ & 50 & $\begin{array}{l}31.6 \\
32.5\end{array}$ & $\begin{array}{l}(7.2) \\
(7.1)\end{array}$ & $5.7(1,94)$ & 0.05 & $0.1(1,96)$ & ns & $7.4(1,96)$ & 0.01 \\
\hline
\end{tabular}

Table 6, various factors (age, years of education, sex, change on depression scale, duration of anaesthesia and days spent in hospital after the first postoperative measurement) did not contribute significantly to the total explained variance in the dependent variables. Similar results were obtained for analysis of the relative change (data not shown), and short-term change (data not shown).

\section{Discussion}

Our data provide evidence that cognitive dysfunction, measured using cognitive tests, occurred in the elderly shortly after operation but not in the long term. The decreased performance of the patient group on speed-related cognitive tests (CST0, SCWT I, SCWT II, LDSTTOT) 1 week after surgery was probably caused by postoperative analgesics, bed rest, inactivity, fasting, sleep deprivation ${ }^{21}$ and postoperative pain, ${ }^{22}$ all of which can have a deleterious effect on cognitive function. Although both groups showed the same or improved performance after 3 months, patients showed more improvement than controls in tests measuring sensorimotor (CSTB) and interference susceptibility (SCWT III) and less improvement in a test measuring processing of general information (LDSTTOT). The relatively greater improvement in patients on two test variables (CSTB and SCWT III) may be because they were experiencing less stress and pain by the 3 month testing. The relatively smaller degree of improvement in patients on one test variable (LDSTTOT) could be an indication of relative deterioration as no change or a relatively greater improvement in this group would be expected. An insufficient number of patients were studied to determine the extent of lack of improvement. This needs to be analysed on a much larger sample.

Our study confirmed the earlier finding of short-term individual cognitive dysfunction after surgery and was of a similar degree. ${ }^{13}$ However, in contrast with these earlier findings, long-term individual cognitive dysfunction was not found. An explanation for this discrepancy is the smaller number of patients and controls in the present study. Another possibility is that there are differences in cognitive decline between different countries. Our study only presents data from the academic hospital in Maastricht (The Netherlands). Future research will study this issue in more detail.

Duration of anaesthesia, days spent in hospital after the first postoperative measurement, age, sex, years of education and change in score on the Zung scale did not predict shortor long-term change in cognitive performance. There was one exception, namely that an increase in depressive symptoms contributed significantly to decreased performance on the CST0. Although this was an isolated finding, the change is in the predicted direction as an increase in depressive symptoms was expected to correlate with decreased per- 
Table 4 Long-term effects of surgery on performance of patients and controls in various tests of cognitive function. For each test, mean (SD) levels are displayed at baseline and 3 months after operation. For CST and SCWT, a higher score indicates a lower test performance. For VVLT and LDST, a lower score indicates a lower test performance

\begin{tabular}{|c|c|c|c|c|c|c|c|c|c|c|c|c|}
\hline & \multicolumn{3}{|c|}{ Patients } & \multicolumn{3}{|c|}{ Controls } & \multicolumn{2}{|l|}{ Group } & \multicolumn{2}{|l|}{ Time } & \multicolumn{2}{|c|}{ Group $\times$ time } \\
\hline & $n$ & Mean & (SD) & $n$ & Mean & (SD) & $\mathbf{F}(\mathbf{d f})$ & $P<$ & F (df) & $P<$ & F (df) & $P<$ \\
\hline \multicolumn{13}{|c|}{ Concept shifting test (CST) } \\
\hline CST0 (s) & 48 & $\begin{array}{l}8.2 \\
7.5\end{array}$ & $\begin{array}{l}(2.6) \\
(2.3)\end{array}$ & 50 & $\begin{array}{l}6.4 \\
6.2\end{array}$ & $\begin{array}{l}(1.2) \\
(1.2)\end{array}$ & $5.6(1,94)$ & 0.05 & $14.5(1,96)$ & 0.001 & $3.2(1,96)$ & ns \\
\hline CSTA (s) & 48 & $\begin{array}{l}25.5 \\
24.9\end{array}$ & $\begin{array}{l}(7.3) \\
(8.1)\end{array}$ & 50 & $\begin{array}{l}21.6 \\
21.6\end{array}$ & $\begin{array}{l}(5.1) \\
(5.8)\end{array}$ & $0.7(1,94)$ & ns & $0.5(1,96)$ & ns & $0.3(1,96)$ & ns \\
\hline $\operatorname{CSTB}(s)$ & 48 & $\begin{array}{l}32.2 \\
29.7\end{array}$ & $\begin{array}{l}(10.9) \\
(10.4)\end{array}$ & 50 & $\begin{array}{l}25.5 \\
26.4\end{array}$ & $\begin{array}{l}(5.8) \\
(8.4)\end{array}$ & $2.0(1,94)$ & ns & $1.1(1,96)$ & ns & $5.0(1,96)$ & 0.05 \\
\hline $\operatorname{CSTC}(\mathrm{s})$ & 47 & $\begin{array}{l}44.2 \\
43.2\end{array}$ & $\begin{array}{l}(15.6) \\
(18.6)\end{array}$ & 49 & $\begin{array}{l}34.5 \\
35.2\end{array}$ & $\begin{array}{r}(10.6) \\
(9.8)\end{array}$ & $2.2(1,92)$ & ns & $0.0(1,94)$ & ns & $0.9(1,94)$ & ns \\
\hline \multicolumn{13}{|c|}{ Visual verbal learning test (VVLT) } \\
\hline VVLTTOT & 48 & $\begin{array}{l}25.1 \\
26.5\end{array}$ & $\begin{array}{l}(6.0) \\
(5.4)\end{array}$ & 49 & $\begin{array}{l}26.8 \\
28.6\end{array}$ & $\begin{array}{l}(5.1) \\
(4.9)\end{array}$ & $1.5(1,93)$ & ns & $13.7(1,95)$ & 0.001 & $0.2(1,95)$ & ns \\
\hline VVLTDEL & 48 & $\begin{array}{l}7.5 \\
8.3\end{array}$ & $\begin{array}{l}(3.1) \\
(3.3)\end{array}$ & 49 & $\begin{array}{l}9.2 \\
9.8\end{array}$ & $\begin{array}{l}(2.5) \\
(2.2)\end{array}$ & $4.1(1,93)$ & 0.05 & $11.2(1,95)$ & 0.01 & $0.1(1,95)$ & ns \\
\hline \multicolumn{13}{|c|}{ Stroop colour-word test (SCWT) } \\
\hline SCWT I (s) & 47 & $\begin{array}{l}17.0 \\
17.3\end{array}$ & $\begin{array}{l}(3.0) \\
(3.3)\end{array}$ & 50 & $\begin{array}{l}18.1 \\
18.2\end{array}$ & $\begin{array}{l}(2.9) \\
(3.1)\end{array}$ & $10.6(1,93)$ & 0.01 & $0.3(1,95)$ & ns & $0.1(1,95)$ & ns \\
\hline SCWT II (s) & 46 & $\begin{array}{l}23.5 \\
22.7\end{array}$ & $\begin{array}{l}(4.2) \\
(4.0)\end{array}$ & 50 & $\begin{array}{l}22.7 \\
21.9\end{array}$ & $\begin{array}{l}(3.5) \\
(2.9)\end{array}$ & $0.1(1,92)$ & ns & $9.8(1,94)$ & 0.01 & $0.0(1,94)$ & ns \\
\hline SCWT III (s) & 47 & $\begin{array}{l}55.8 \\
46.9\end{array}$ & $\begin{array}{l}(20.1) \\
(12.7)\end{array}$ & 50 & $\begin{array}{l}37.5 \\
35.1\end{array}$ & $\begin{array}{l}(8.2) \\
(8.6)\end{array}$ & $21.2(1,93)$ & 0.001 & $30.3(1,95)$ & 0.001 & $9.9(1,95)$ & 0.01 \\
\hline \multicolumn{13}{|c|}{ Letter-digit substitution test (LDST) } \\
\hline LDSTTOT & 48 & $\begin{array}{l}26.2 \\
27.8\end{array}$ & $\begin{array}{l}(7.4) \\
(7.4)\end{array}$ & 50 & $\begin{array}{l}31.6 \\
34.8\end{array}$ & $\begin{array}{l}(7.2) \\
(6.8)\end{array}$ & $5.8(1,94)$ & 0.05 & $59.2(1,96)$ & 0.001 & $6.9(1,96)$ & 0.01 \\
\hline
\end{tabular}

formance..$^{23}$ Although long-term cognitive dysfunction, measured using the cognitive tests, was not found, $17 \%$ of patients reported a subjective decrease in cognitive function 6 months after surgery.

Despite the use of parallel test versions, healthy controls and sensitive tests, a discrepancy between cognitive complaints and cognitive test performance was found. These cognitive complaints are perhaps related to factors other than objective test performance. The operation could trigger several psychological events (e.g. mild depression or awareness of age-related changes), which could lead to subjective feelings of cognitive dysfunction not associated with impaired performance on cognitive tests. The experience of an unexpected cognitive decline shortly after operation may worry patients and lead to cognitive complaints. If this is true, patients should be given information about what to expect after an operation. Medical, psychological or neuropsychological interventions could be important in this respect. Others have found that patients who had more knowledge of surgery had fewer worries and recovered faster. ${ }^{8}$ This could also affect the percentage of patients reporting subjective cognitive dysfunction.

Earlier studies rarely examined subjective reports and objective performance together. One study examined if patients who reported cognitive complaints after cardiac surgery showed cognitive dysfunction, assessed using cog-
Table 5 Short-term (7 days) and long-term (3 months) individual postoperative cognitive dysfunction (POCD) for patients $(n=48)$ and controls $(n=50)$. $* * P<0.01$

\begin{tabular}{|c|c|c|c|c|c|c|}
\hline & \multicolumn{3}{|c|}{ Short-term } & \multicolumn{3}{|c|}{ Long-term } \\
\hline & \multicolumn{3}{|c|}{ Patients Controls } & \multicolumn{3}{|c|}{ Patients Controls } \\
\hline & $n(\%)$ & $n(\%)$ & $\begin{array}{l}\text { Chi- } \\
\text { square }\end{array}$ & $n(\%)$ & $n(\%)$ & $\begin{array}{l}\text { Chi- } \\
\text { square }\end{array}$ \\
\hline POCD absent & $35(73)$ & 47 (94) & $7.97 * *$ & $44(92)$ & $48(94)$ & $2.03(\mathrm{~ns})$ \\
\hline POCD present & $13(27)$ & $3(6)$ & & $4(8)$ & $1(2)$ & \\
\hline
\end{tabular}

nitive tests. ${ }^{24}$ They found that patients who considered that this aspect of their cognitive function had deteriorated were not found to have reduced function, as assessed by cognitive tests 12 months after surgery. When mood state was examined, it was found that patients who reported deterioration tended to have higher levels of depression and anxiety. The authors concluded that subjective reports of cognitive dysfunction after heart surgery do not reflect actual changes in cognitive function but rather appear to be related to mood. It was also found that increased emotional arousal (anxiety and depression) in patients undergoing cardiac surgery had no relevant effect on their cognitive test performance. ${ }^{25}$ Although levels of anxiety and depression 
Table 6 Results of regression analysis of several background variables on performance change from baseline to 3 months (long-term) after surgery. Chronological age, sex $(m=1, f=2)$ and years of education (Edu.) were entered in step one, change in score on the depression scale in step two, and duration of anaesthesia (Dur.) and days spent in hospital after the first postoperative measurement (Dif.) in the final step. Shown are standardized regression coefficients (beta) in the final model and the explained variance $\left(r^{2}\right)$ after each step, for long-term cognitive change. $* * P<0.01$

\begin{tabular}{|c|c|c|c|c|c|c|c|c|c|}
\hline \multirow[b]{2}{*}{ Long-term change } & \multicolumn{3}{|l|}{ Step 1} & \multirow{2}{*}{$\begin{array}{l}\text { Step } 2 \\
\text { Zung }\end{array}$} & \multicolumn{2}{|c|}{ Step 3} & \multicolumn{3}{|c|}{$r^{2}$, after step } \\
\hline & Edu. & Age & Sex & & Dif. & Dur. & 1 & 2 & 3 \\
\hline CST0 & 0.01 & 0.02 & 0.31 & $0.42^{* *}$ & -0.14 & 0.23 & 0.020 & $0.177 * *$ & 0.217 \\
\hline CSTA & 0.02 & 0.15 & -0.34 & -0.07 & 0.08 & -0.40 & 0.023 & 0.026 & 0.128 \\
\hline CSTB & 0.13 & 0.09 & -0.02 & 0.17 & -0.18 & -0.10 & 0.018 & 0.042 & 0.08 \\
\hline CSTC & 0.14 & -0.22 & -0.09 & 0.04 & 0.14 & -0.18 & 0.079 & 0.082 & 0.111 \\
\hline VVLTTOT & 0.10 & -0.13 & -0.07 & -0.16 & -0.18 & -0.17 & 0.052 & 0.080 & 0.142 \\
\hline VVLTDEL & -0.10 & -0.07 & 0.12 & -0.12 & -0.17 & 0.10 & 0.035 & 0.051 & 0.078 \\
\hline SCWT I & 0.18 & -0.19 & 0.20 & -0.03 & -0.16 & 0.32 & 0.066 & 0.066 & 0.136 \\
\hline SCWT II & -0.06 & 0.06 & 0.11 & 0.04 & 0.09 & 0.04 & 0.015 & 0.017 & 0.026 \\
\hline SCWT III & -0.21 & -0.12 & 0.26 & 0.25 & -0.17 & 0.22 & 0.059 & 0.112 & 0.158 \\
\hline LDSTTOT & -0.02 & 0.21 & 0.28 & 0.06 & -0.11 & -0.16 & 0.146 & 0.148 & 0.186 \\
\hline
\end{tabular}

do not seem to affect cognitive test performance, they can have an impact on cognitive complaints.

Other complex factors, such as degree of emotional support, the patient's financial situation and degree to which the surgical procedure improves the elderly patient's social integration, may influence cognitive outcome and effects on the nervous system in the long term. ${ }^{26}$ The preoperative level of function, psychosocial variables such as social network, coping style, personality and expectations of the operation, need to be analysed in larger studies. Little attention has been paid to these factors and therefore their importance is unclear.

A final explanation for the discrepancy between subjective reports of cognitive function and assessed cognitive performance is that not much time is available for cognitive assessment. It is possible that patients are able to perform quite well during a short period, by putting much effort into their performance, but that their daily functioning is compromised and gives rise to cognitive complaints. In other words, patients are able to mobilize cognitive resources for a short time during the testing session, but they are not able to sustain this for a prolonged period. This hypothesis is difficult to investigate in a hospital setting.

Although most patients recover from surgery under general anaesthesia, a subgroup of patients suffer long-term self-reported cognitive complaints. Identification of those patients at risk and possible interventions to reduce these complaints should be the main goal of future research. The apparent negative findings concerning objective cognitive test performance can have positive implications for possible interventions to reduce or prevent long-term cognitive complaints.

\section{Acknowledgements}

This work was supported by a grant from the Maastricht University Hospital Foundation. We thank Inge Crolla and Patricia Hameleers for assistance in the collection of the cognitive and patient data.

\section{References}

1 Bedford PD. A dverse cerebral effects of anaesthesia on old people. Lancet 1955; 6: 259-63

2 Dierks-Ventling VC, Gerhard U, Hobi V. Der Einfluss von Totalund Regionalanasthesie auf Konzentration und Gedõchtnis (The effects of total- and local anesthesia on concentration and memory). Schweiz Z Psychol 1989; 48: 112-20

3 Meier U, Trüllinger E, Stoll F, Fassolt A. Zur Frage der postoperativen konzentrations- und gedächtnisstörungen bei chirurgische patienten. Schweiz Z Psychol 1986; 45: 103-18

4 Møller JT, Svennild I, Johannessen NW, et al. Perioperative monitoring with pulse oximetry and late postoperative cognitive dysfunction. Br J Anaesth 1993; 71: 340-7

5 Parikh SS, Chung F. Postoperative delirium in the elderly. Anesth Analg 1995; 80. 1217-22

6 Dyer CB, Ashton CM, Teasdale TA. Postoperative delirium: A review of 80 primary data-collection studies. Arch Intern Med 1995; 155: 461-5

7 W illiams-Russo P, Sharrock N E, Mattis S, Szatrowski TP, C har Isson ME. Cognitive effects after epidural vs general anesthesia in older adults. JAM A 1995; 274: 44-50

8 C ampbell DN C, Lim M, Muir MK, et al. A prospective randomised study of local versus general anaesthesia for cataract surgery. Anaesthesia 1993; 48: 422-8

9 Chung $F$, Chung $A$, Meier RH, Lautenschlaeger $E$, Seyone C. Comparison of perioperative mental function after general anaesthesia and spinal anaesthesia with intravenous sedation. Can J Anaesth 1989; 36: 382-7

10 Folstein MF, Folstein, SE, McHugh PR. 'Mini-Mental State': A practical method for grading the cognitive state of patients for the clinician. J Psychiatr Res 1975; 12: 189-98

11 W allace LM. Communication variables in the design of pre-surgical preparatory information. $\mathrm{Br}$ J Clin Psychol 1986; 25: 111-18

12 Krier C, Böhrer H, Polarz H, Schönstedt R. Cognitive function in geriatric ophthalmological patients following local versus general anesthesia. Ophthalmologie 1993; 90: 367-71

13 Møller JT, Cluitmans P, Rasmussen LS, et al. Long-term postoperative cognitive dysfunction in the elderly: ISPO CD 1 study. Lancet 1998; 352: 857-61

14 Brand $\mathrm{N}$, Jolles J. Learning and retrieval rate of words presented auditorily and visually. J Gen Psychol 1985; 112: 201-10 
15 Bohnen N, Jolles J, Twijnstra A. Modification of stroop colour word test improves differentiation between patients with mild head injury and matched controls. Clin Neuropsychol 1992; 6: 178-84

16 Reitan RM. Validity of the trail making test as an indicator of organic brain damage. Percept M ot Skills 1958; 8: 271-6

17 Lezak MD. Neuropsychological Assessment, 3rd Edn. N ew York: O xford U niversity Press, 1995

18 Zung W W K, D urham N C, Richards CB, Coral Gables FLA, Short MJ. Self-rating depression scale in an outpatient clinic. Arch Gen Psychiatry 1965; 13: 508-15

19 Jolles J, Houx PJ, Van Boxtel MP, Ponds RW. The Maastricht Aging Study: Determinants of Cognitive Aging. Maastricht: Neuropsych Publishers, 1995

20 Shaw PJ, Bates D, Cartlidge EF, et al. Long-term intellectual dysfunction following coronary artery bypass graft surgery: a six month follow-up study. Q J Med 1987; 62: 259-68
21 Edwards H, Rose E, Schorow M, King TC. Postoperative deterioration in psychomotor function. JAM A 1981; 245: 1342-3

22 Smith C, C arter M, Sebel P, Y ate P. Mental function after general anaesthesia for transurethral procedures. $\mathrm{Br}$ J Anaesth 1991; 67: 262-8

23 Newman PJ, Sweet JJ. Depressive disorders. In: Puente AE, McC affrey RJ, eds. Handbook of Neuropsychological Assessment: A Biopsychosocial Perspective. New York: Plenum Press, 1992; 263-307

24 N ewman $S$, Klinger $L$, Venn $G$, Smith $P$, Harrison $M$, Treasure $T$. Subjective reports of cognition in relation to assessed cognitive performance following coro nary artery bypass surgery. J Psychosom Res 1989; 33: 227-33

25 Vingerhoets G, De Soete G, Jannes C. Relationship between emotional variables and cognitive test performance before and after open-heart surgery. Clin Neuropsychol 1995; 9. 198-202

26 Muravchick S. Immediate and long-term nervous system effects of anesthesia in elderly patients. Clin Anesth 1986; 4: 1035-45 